\title{
Vascular transcription factors guide plant epidermal responses to limiting phosphate conditions
}

\author{
Jos R. Wendrich,2*, BaoJun Yang ${ }^{1,2 *}$, Niels Vandamme ${ }^{3,4 *}$, Kevin Verstaen ${ }^{3,4 *}$, Wouter Smet ${ }^{1,2}$, \\ Celien Van de Velde ${ }^{1,2}$, Max Minne, ${ }^{1,2}$, Brecht Wybouw ${ }^{1,2}$, Eliana Mor ${ }^{1,2}$, Helena E. Arents ${ }^{1,2}$, Jonah Nolf ${ }^{1,2}$, \\ Julie Van Duyse ${ }^{5,6}$, Gert Van Isterdael ${ }^{5,6}$, Steven Maere ${ }^{1,2}$, Yvan Saeys ${ }^{3,4}+$, Bert De Rybel ${ }^{1,2} \uparrow$ \\ ${ }^{1}$ Department of Plant Biotechnology and Bioinformatics, Ghent University, Ghent, Belgium. ${ }^{2}$ VIB Center for Plant Systems Biology, Ghent, Belgium. ${ }^{3}$ Data Mining and \\ Modelling for Biomedicine, VIB Center for Inflammation Research, Ghent, Belgium. ${ }^{4}$ Department of Applied Mathematics, Computer Science and Statistics, Ghent \\ University, Ghent, Belgium. ${ }^{5}$ IB Flow Core, VIB Center for Inflammation Research, Ghent, Belgium. ${ }^{6}$ Department of Biomedical Molecular Biology, Ghent University, Ghent, \\ Belgium. \\ *These authors contributed equally to this work. †Corresponding author. Email: beryb@psb.vib-ugent.be (B.D.R.); yvan.saeys@irc.vib-ugent.be (Y.S.)
}

Optimal plant growth is hampered by deficiency of the essential macronutrient phosphate in most soils. Plant roots can, however, increase their root hair density to efficiently forage the soil for this immobile nutrient. By generating and exploiting a high-resolution single-cell gene expression atlas of Arabidopsis roots, we show an enrichment of TARGET OF MONOPTEROS 5 / LONESOME HIGHWAY (TMO5/LHW) target gene responses in root hair cells. The TMO5/LHW heterodimer triggers biosynthesis of mobile cytokinin in vascular cells and increases root hair density during low phosphate conditions by modifying both the length and cell fate of epidermal cells. Moreover, root hair responses in phosphate deprived conditions are TMO5 and cytokinin dependent. In conclusion, cytokinin signaling links root hair responses in the epidermis to perception of phosphate depletion in vascular cells.

Vascular cell proliferation in plant roots is, in part, controlled by the heterodimer complex formed by TARGET OF MONOPTEROS 5 and LONESOME HIGHWAY (TMO5/LHW) (1-7). This complex is required and sufficient to control cell proliferation by inducing expression of the direct downstream target LONELY GUY4 (LOG4) and its close homolog LOG3 $(1,6)$, which encode rate-limiting enzymes in the final conversion step of the phytohormone cytokinin into its bioactive form $(8,9)$. The TMO5/LHW complex is limited to xylem cells, which produce cytokinin but are themselves insensitive to cytokinin. The xylem-produced cytokinin diffuses to neighboring procambium cells, where it promotes cell proliferation via induction of DOF-type transcription factors $(10,11)$. As the TMO5/LHW pathway induces production of cytokinin as mobile intermediate that functions in neighboring cells, the target genes (11) in this hormone signaling cascade are likely to be expressed in various cell types surrounding the xylem and perhaps even outside of the vascular bundle. Here we used single cell RNA-sequencing to probe the tissue specific TMO5/LHW signaling output in Arabidopsis root meristems and found that this vascular heterodimer complex is required for the root hair responses to phosphate deficit conditions. We show how cytokinin signaling links vascular perception of limiting phosphate to epidermal responses allowing plants to efficiently forage the soil for this immobile macronutrient.

\section{Single cell RNA-sequencing analysis}

We generated a high-resolution single cell RNA-sequencing
(scRNA-seq) atlas of the wild type Arabidopsis root tip (1216), making use of the 10X Genomics Chromium technology (fig. S1A). Following protoplast isolation, sorted cells were collected and processed for single cell transcriptomics (see supplementary materials for details). In summary, a total population of 15,918 cells were recovered across three replicates and next filtered to retain 5,145 high quality cells with unique molecular identifier (UMI) counts > 17,290 (fig. S1B). Taking into account only these high quality cells, a total of 21,492 genes were detected in our root meristem dataset, covering nearly $80 \%$ of the genome, with a median expression of 6,781 genes per cell and a mean of 208,937 reads per cell (Fig. 1A). Unsupervised clustering and $t$-distributed stochastic neighbor-embedding (tSNE) projections were performed on the 5,145 high quality single cells, recovering distinct clusters of cells (Fig. 1A).

Following quality control (see supplementary materials and fig. S1, C to E), cell type annotation and cluster identification were performed by mapping the top 20 differentially expressed genes (DEG) for each cluster (compared to the rest of the dataset) on a publicly available bulk RNA-seq dataset (17) of the Arabidopsis root. This resulted in an annotated dataset representing all major cell types in the root, including quiescent center cells (Fig. 1A and fig. S1F). The annotations were confirmed for all cell identities by the observed expression of key signature marker genes and in vivo expression of 41 newly generated promoter reporter lines (Fig. 1B, figs. S2 to S12, and table S1). Moreover, cells undergoing division are 
found in two specific sub-clusters (Fig. 1), indicating that their transcriptomes are more similar to each other than the actual cell identity determinants of the transcriptome. In summary, the scRNA-seq dataset contains clusters of all cell types of the root meristem which were identified according to predicted in vivo expression patterns and were validated using a set of newly generated reporter lines.

\section{Trajectory analysis establishes a blueprint of cell line- ages}

We next used trajectory analyses to refine identification of cell types and developmental transitions within each cell identity cluster. We first analyzed xylem (251 cells; 5\%; fig. S3A) and phloem (388 cells; 8\%; fig. S4A) cell lineages, as these undergo identity changes throughout development. Xylem initial cell lineages branch into proto- and metaxylem identities, which differ in their subsequent differentiation processes including secondary cell wall generation (18). Phloem cell initials undergo several oriented divisions, generating lineages that branch to generate phloem procambium, sieve elements and companion cells (19, 20). The complexity of both these cell types was captured in the inferred trajectories and gene expression patterns of the reporter lines validated inferred developmental trajectories and sub-cluster identities (figs. S3 and S4; see supplementary materials for details). Similar analyses validated trajectories for the procambium, pericycle, endodermis, cortex, epidermis, lateral root cap and columella clusters (Fig. 1A and figs. S5 to S11).

As many root cell types in Arabidopsis increase in ploidy with development (21), the developmental trajectories for these cell types should correspond to trajectories of increasing cellular endoreplication levels. Thus, to further validate our trajectories, we predicted the endoreplication state of each cell based on the expression of a validated set of endoreplication markers (21) (see supplementary materials for details) and superimposed the predicted cell ploidy on the tSNE plot (Fig. 1C). Developmental trajectories of cortex, endodermis, pericycle, epidermis/atrichoblast, lateral root cap and xylem clusters exhibit clear ploidy transitions (Fig. 1C); validating these trajectories and their orientation. For the procambium cell cluster, correspondence between developmental trajectories and ploidy was less evident. For the phloem cell lineage, which undergoes continuous divisions as it passes through the meristem, no correlation was found. Cells in the quiescent center and hair cell (trichoblast) clusters mostly contained $2 \mathrm{C}$ and $16 \mathrm{C}$ cells, respectively (Fig. 1C).

In conclusion, both newly generated reporter lines and ploidy analysis confirm the inferred developmental trajectories of all main cell identities. Our results thus allow the identification of distinct sub-clusters linked to the developmental stage of each cell identity; establishing a developmental blueprint for all root cell lineages, including progenitor populations for several cell identities.

\section{TMO5/LHW targets are enriched in root hair cells}

We next intersected our scRNA-seq root dataset with the set of 273 genes identified via bulk transcriptome analysis to be induced upon TMO5/LHW induction (11). About 80 target genes $(29 \%)$ were predicted to be expressed in root hair (trichoblast) cells, of which 47 (17\%) were expressed only in trichoblast cells (Fig. 2A and fig. S13). Such expression patterns were not expected in relation to literature on TMO5/LHW function in vascular proliferation $(1,2,5,6)$ and the overlapping expression domain in the young xylem cells (2). We confirmed the induction and expression pattern of a subset of these genes by Q-RT-PCR and promoter-GFP fusions respectively (Fig. 2B and fig. S14A). The trichoblast specific expression patterns of these target genes thus suggests a putative role for TMO5/LHW in the regulation of root hair development or patterning. Although homozygous tmo5 single and tmo5 tmo5-like1 double mutants showed normal root hair densities under standard growth conditions (high phosphate, HP), misexpression of TMO5 and $L H W$ in all cells of the root meristem (pRPS5A::TMO5-GR x pRPS5A::LHW-GR or dGR) resulted in a strong increase in root hair density (Fig. 2, C and D); while misexpression of unrelated bHLH factors did not result in this root hair density increase (fig. S15). A strong increase in root hair density can also be observed in wild type roots grown on phosphate limiting conditions (Fig. 2, C and D, and table S2; see fig. S16 and supplementary materials for a detailed description of 3D root hair quantifications) (22-24). Auxin biosynthesis, transport and signaling are all required for this root hair response to phosphate limiting conditions (22): auxin signaling is induced upon low phosphate conditions in the columella/lateral root cap region and in xylem cells, where the TMO5/LHW dimer is active (2, 4). Auxin-dependent TMO5 function is required for the root hair response to low phosphate, as tmo5 tmo5-like1 double mutants were less sensitive to these limiting conditions (Fig. 2, C and D, and table S2). Phosphate starvation genes (25) were however still induced in this mutant background (fig. S14B), suggesting that perception was unaffected. Moreover, induction of several root hair specific TMO5/LHW target genes was tmo5 tmo5-like1 dependent (fig. S14C). The TMO5 homologs seem redundantly required for this response, as we found no significant difference in root hair density between wild type and the tmo5 single mutant on low phosphate (Fig. 2, C and D) (26). Taken together, these results show that the increase in root hair density upon low phosphate conditions specifically requires TMO5 activity. Because low phosphate conditions have also been associated with changes in root hair length (27), we quantified this parameter in our mutant lines and treatments and found similar responses (fig. S14D; 
see fig. S16 and supplementary materials for details on quantification). Thus, activity of the TMO5/LHW complex is required for the complete root hair response to low phosphate conditions.

To understand the cellular basis of the root hair density increase in response to low phosphate conditions, we quantified several parameters that could contribute to this effect (including root length, meristem length and epidermal cell length; Fig. 2E and figs. S14, E and F, and S16) in wild type and tmo5 tmo5-like1 roots. Although the tmo5 tmo5-like1 mutant showed reduced root and meristem length in control conditions compared to wild type, this did not result in altered root hair densities (Fig. 2D and fig. S14, E and F). This suggests that root and meristem length are not directly contributing to changes in root hair density. Fitting with the observed changes in root hair density, epidermal cell length was not different in wild type and tmo5 tmo5-like1 under control conditions, was decreased in low phosphate conditions in wild type, and significantly less decreased in the tmo5 tmo5like1 double mutant (Fig. 2E). Similar results were obtained upon dGR induction (Fig. 2E). These results suggest that a reduction of epidermal cell length in the root hair zone drives the low phosphate response leading to an increase in root hair density.

\section{TMO5/LHW dependent cytokinin controls root hair re- sponses to low phosphate}

To understand how TMO5/LHW in the xylem might be involved in the low phosphate response of root hairs in the epidermis, we analyzed expression of the transcriptional pTMO5::n3GFP reporter line (28). TMO5 expression increased in response to low phosphate conditions (29) (Fig. 3, $\mathrm{A}$ and $\mathrm{B})$, consistent with the reported increase in auxin signaling under these limiting conditions (22) and the auxin-inducibility of TMO5 (2). No ectopic expression of TMO5 was observed in the trichoblast cells (Fig. 3A). Furthermore, increasing TMO5 levels only in the xylem axis or in the vascular bundle [using pTMO5::TMO5:GR (1) or using newly generated $\mathrm{pSHR}:$ TMO5:GR and $\mathrm{p} W O L:: \mathrm{XVE}>>\mathrm{TMO} 5$ lines], was sufficient to increase root hair density (Fig. 3, C to E, and fig. $\mathrm{S} 17, \mathrm{~A}$ to C). This suggests that the effect of TMO5 on the low phosphate induced root hair density increase is cell non-autonomous.

The TMO5/LHW complex binds the LOG4 promoter, thus promoting cytokinin biosynthesis. Cytokinin can then diffuse to neighboring cells where its perception induces cell proliferation $(1,6)$. To investigate if low phosphate conditions might lead to an increased induction of the cytokinin signaling pathway in epidermal cells, we analyzed the pTCSn::ntdTomato cytokinin-signaling reporter $(11,30)$. In low phosphate conditions, the TCSn reporter was induced in the epidermal cells of the root meristem (Fig. 4A).
Additionally, A-type ARRs (including $A R R 4,5,6,8,9,12$ and 15), that our scRNA-seq dataset showed to be expressed in trichoblast cells, were up-regulated upon TMO5/LHW induction (11) (figs. S13 and S14A). Additionally, expression of three trichoblast-restricted TMO5/LHW target genes was found to be induced by exogenous cytokinin treatment (fig. S18A), fitting with published data (31). These results suggest an increased induction of the cytokinin signaling pathway in the epidermis under low phosphate conditions and fit with the published effect of cytokinin on cell length (32). To show that increased cytokinin levels and/or signaling might lead to an increase in root hair density due to a reduction in epidermal cell lengths, we next treated wild type roots with $0.1 \mu \mathrm{M} 6$ benzylaminopurine, a synthetic cytokinin. Indeed, treatment with cytokinin in high phosphate conditions mimicked the root hair density promoting effect of low phosphate conditions (Fig. 4B) and a reduction in epidermal cell length (fig. S18B). Additionally, cytokinin was sufficient to rescue the root hair density and epidermal cell length effects to low phosphate-like responses in the tmo5 tmo5-like1 double mutant (Fig. 4B and fig. S18B). To investigate the possible role of ethylene in this response (33), we next analyzed the responses of the ein3 eill double mutant in downstream ethylene signaling on low phosphate medium and upon cytokinin treatment and found no difference compared to wild type plants (fig. S19A), fitting with published reports that cytokinin effects on root hair length are not dependent on ethylene signaling (34) and the fact that ethylene response markers (33) were not uniformly altered upon TMO5/LHW induction (fig. S19B). Given that the upstream ein2 receptor single mutant does show some resistance to cytokinin but not low phosphate treatment (fig. S19A), we cannot rule out involvement of complex cytokinin-ethylene hormonal cross-talk during this developmental process.

To provide additional genetic support for the hypothesis that cytokinin signaling in trichoblast cells drives the root hair response to low phosphate conditions in a TMO5dependent manner, we first reduced cytokinin levels by analyzing the $\log 347$ triple biosynthesis mutant ( 8 ) or by increasing levels of the CKX3 cytokinin conjugating enzyme (35) by analyzing a newly generated $\mathrm{p} R P S 5 A:$ :CKX3 transgenic line. Both genetic tools to reduce cytokinin levels resulted in an inhibition of the low phosphate response (Fig. 4C and fig. S18C). To strengthen that vascular-derived cytokinin is responsible for the root hair response to low phosphate conditions, we generated a vascular specific estradiol inducible LOG4 transgenic line (pWOL::XVE >>LOG4). Upon induction of the cytokinin biosynthetic gene LOG4 only in the vascular domain, an increase in root hair density was observed (Fig. 4D). Additionally, we complemented the $\log 1234578$ heptuple mutant (9), which has very low levels of active cytokinin, with LOG4 expressed only in the TMO5 domain (1). In 
phosphate limiting conditions, pTMO5::LOG4 expression was sufficient to restore a wild type-like response (fig. S20). Taken together, these experiments show that vascular-derived cytokinin is capable of triggering responses in the trichoblast cells. Thus, vascular-derived cytokinin can drive the root hair response to low phosphate conditions in a TMO5-dependent manner.

Previously, prolonged low phosphate conditions were shown to increase the number of cortex cell files and modify epidermal cell fates (36). To understand if these parameters might contribute to our observed increase in root hair density, we first analyzed the number of cells in radial sections of cortex and epidermal cell files as these determine the number of root hairs (36). Although prolonged growth in phosphate deprived conditions leads to an increase in the number of cortex cells (36) (fig. S21), this was not observed after 10 days, a time point used in all our experiments (table S2); suggesting that the effects observed in our experiments are not due to additional cortex cells. We next examined the possible change in cell fate by examination of epidermal cell identity using markers for hair (pCOBL9::GFP) (37) and non-hair (pGL2::GFP) (38) cell files. Epidermal cell identities were mixed upon cytokinin treatment, similar to the effect of low phosphate conditions (Fig. 5, A to C) (36). This cytokinin-dependent effect most likely feeds into the known pathways determining epidermal cell identity, as cytokinin treatment was not able to induce hair formation in the cpc try double mutant (fig. S22) (39). Moreover, significantly more root hairs were formed in non-hair positions upon dGR induction, exogenous cytokinin treatment and low phosphate conditions (Fig. 5D). This low phosphate effect was absent in the tmo5 tmo5-like1 mutant and in plants with reduced cytokinin signaling levels (Fig. 5, D and E). These results suggest that alterations in the epidermal cell identity contribute to the observed increase in root hair density upon low phosphate conditions.

\section{Outlook}

Here we showed that the vascular bHLH heterodimer TMO5/LHW controls root hair density by modifying epidermal cell length and cell fates. Phosphate deficit may trigger increased auxin signaling in xylem cells, inducing the TMO5/LHW pathway and downstream local cytokinin biosynthesis. Cytokinin may then diffuse outwards to direct length and fates of outer trichoblast cells. As such, this hormone signaling cascade spans multiple tissue layers in the meristem to regulate roots foraging for phosphate.

\section{REFERENCES AND NOTES}

1. B. De Rybel, M. Adibi, A. S. Breda, J. R. Wendrich, M. E. Smit, O. Novák, N. Yamaguchi, S. Yoshida, G. Van Isterdael, J. Palovaara, B. Nijsse, M. V. Boekschoten, G. Hooiveld, T. Beeckman, D. Wagner, K. Ljung, C. Fleck, D. Weijers, Integration of growth and patterning during vascular tissue formation in Arabidopsis. Science 345, 1255215 (2014). doi:10.1126/science.1255215 Medline
2. B. De Rybel, B. Möller, S. Yoshida, I. Grabowicz, P. Barbier de Reuille, S. Boeren, R. S. Smith, J. W. Borst, D. Weijers, A bHLH complex controls embryonic vascular tissue establishment and indeterminate growth in Arabidopsis. Dev. Cell 24, 426437 (2013). doi:10.1016/i.devcel.2012.12.013 Medline

3. K. Ohashi-Ito, D. C. Bergmann, Regulation of the Arabidopsis root vascular initial population by LONESOME HIGHWAY. Development 134, 2959-2968 (2007). doi:10.1242/dev.006296 Medline

4. K. Ohashi-Ito, M. Matsukawa, H. Fukuda, An atypical bHLH transcription factor regulates early xylem development downstream of auxin. Plant Cell Physiol. 54, 398-405 (2013). doi:10.1093/pcp/pct013 Medline

5. K. Ohashi-Ito, M. Oguchi, M. Kojima, H. Sakakibara, H. Fukuda, Auxin-associated initiation of vascular cell differentiation by LONESOME HIGHWAY. Development 140, 765-769 (2013). doi:10.1242/dev.087924 Medline

6. K. Ohashi-Ito, M. Saegusa, K. Iwamoto, Y. Oda, H. Katayama, M. Kojima, H. Sakakibara, H. Fukuda, A bHLH complex activates vascular cell division via cytokinin action in root apical meristem. Curr. Biol. 24, 2053-2058 (2014). doi:10.1016/i.cub.2014.07.050 Medline

7. F. Vera-Sirera, B. De Rybel, C. Úrbez, E. Kouklas, M. Pesquera, J. C. ÁlvarezMahecha, E. G. Minguet, H. Tuominen, J. Carbonell, J. W. Borst, D. Weijers, M. A. Blázquez, A bHLH-based feedback loop restricts vascular cell proliferation in plants. Dev. Cell 35, 432-443 (2015). doi:10.1016/i.devcel.2015.10.022 Medline

8. T. Kuroha, H. Tokunaga, M. Kojima, N. Ueda, T. Ishida, S. Nagawa, H. Fukuda, K. Sugimoto, H. Sakakibara, Functional analyses of LONELY GUY cytokininactivating enzymes reveal the importance of the direct activation pathway in Arabidopsis. Plant Cell 21, 3152-3169 (2009). doi:10.1105/tpc.109.068676 Medline

9. H. Tokunaga, M. Kojima, T. Kuroha, T. Ishida, K. Sugimoto, T. Kiba, H. Sakakibara, Arabidopsis lonely guy (LOG) multiple mutants reveal a central role of the LOGdependent pathway in cytokinin activation. Plant J. 69, 355-365 (2012). doi:10.1111/j,1365-313X.2011.04795.x Medline

10. S. Miyashima, P. Roszak, I. Sevilem, K. Toyokura, B. Blob, J. O. Heo, N. Mellor, H. Help-Rinta-Rahko, S. Otero, W. Smet, M. Boekschoten, G. Hooiveld, K. Hashimoto, O. Smetana, R. Siligato, E.-S. Wallner, A. P. Mähönen, Y. Kondo, C. W. Melnyk, T. Greb, K. Nakajima, R. Sozzani, A. Bishopp, B. De Rybel, Y. Helariutta, Mobile PEAR transcription factors integrate positional cues to prime cambial growth. Nature 565, 490-494 (2019). doi:10.1038/s41586-018-0839-y Medline

11. W. Smet, I. Sevilem, M. A. de Luis Balaguer, B. Wybouw, E. Mor, S. Miyashima, B. Blob, P. Roszak, T. B. Jacobs, M. Boekschoten, G. Hooiveld, R. Sozzani, Y. Helariutta, B. De Rybel, DOF2.1 controls cytokinin-dependent vascular cell proliferation downstream of TM05/LHW. Curr. Biol. 29, 520-529.e6 (2019). doi:10.1016/i.cub.2018.12.041 Medline

12. K. Jean-Baptiste, J. L. McFaline-Figueroa, C. M. Alexandre, M. W. Dorrity, L. Saunders, K. L. Bubb, C. Trapnell, S. Fields, C. Queitsch, J. T. Cuperus, Dynamics of gene expression in single root cells of Arabidopsis thaliana. Plant Cell 31, 9931011 (2019). doi:10.1105/tpc.18.00785 Medline

13. T. Denyer, X. Ma, S. Klesen, E. Scacchi, K. Nieselt, M. C. P. Timmermans, Spatiotemporal developmental trajectories in the Arabidopsis root revealed using high-throughput single-cell RNA sequencing. Dev. Cell 48, 840-852.e5 (2019). doi:10.1016/i.devcel.2019.02.022 Medline

14. T. Q. Zhang, Z. G. Xu, G. D. Shang, J. W. Wang, A single-cell RNA sequencing profiles the developmental landscape of Arabidopsis root. Mol. Plant 12, 648-660 (2019). doi:10.1016/i.molp.2019.04.004 Medline

15. K. H. Ryu, L. Huang, H. M. Kang, J. Schiefelbein, Single-cell RNA sequencing resolves molecular relationships among individual plant cells. Plant Physiol. 179, 1444-1456 (2019). doi:10.1104/pp.18.01482 Medline

16. C. N. Shulse, B. J. Cole, D. Ciobanu, J. Lin, Y. Yoshinaga, M. Gouran, G. M. Turco, Y. Zhu, R. C. O'Malley, S. M. Brady, D. E. Dickel, High-throughput single-cell transcriptome profiling of plant cell types. Cell Rep. 27, 2241-2247.e4 (2019). doi:10.1016/i.celrep.2019.04.054 Medline

17. S. Li, M. Yamada, X. Han, U. Ohler, P. N. Benfey, High-resolution expression map of the Arabidopsis root reveals alternative splicing and lincRNA regulation. Dev. Cell 39, 508-522 (2016). doi:10.1016/i.devcel.2016.10.012 Medline

18. R. Ruonala, D. Ko, Y. Helariutta, Genetic networks in plant vascular development. Annu. Rev. Genet. 51, 335-359 (2017). doi:10.1146/annurev-genet-120116$\underline{024525}$ Medline 
19. A. Rodriguez-Villalon, B. Gujas, Y. H. Kang, A. S. Breda, P. Cattaneo, S. Depuydt, C. S. Hardtke, Molecular genetic framework for protophloem formation. Proc. Natl. Acad. Sci. U.S.A. 111, 11551-11556 (2014). doi:10.1073/pnas.1407337111 Medline

20. A. P. Mähönen, M. Bonke, L. Kauppinen, M. Riikonen, P. N. Benfey, Y. Helariutta, A novel two-component hybrid molecule regulates vascular morphogenesis of the Arabidopsis root. Genes Dev. 14, 2938-2943 (2000). doi:10.1101/gad.189200 Medline

21. R. Bhosale, V. Boudolf, F. Cuevas, R. Lu, T. Eekhout, Z. Hu, G. Van Isterdael, G. M. Lambert, F. Xu, M. K. Nowack, R. S. Smith, I. Vercauteren, R. De Rycke, V. Storme, T. Beeckman, J. C. Larkin, A. Kremer, H. Höfte, D. W. Galbraith, R. P. Kumpf, S. Maere, L. De Veylder, A spatiotemporal DNA endoploidy map of the Arabidopsis root reveals roles for the endocycle in root development and stress adaptation. Plant Cell 30, 2330-2351 (2018). doi:10.1105/tpc.17.00983 Medline

22. R. Bhosale, J. Giri, B. K. Pandey, R. F. H. Giehl, A. Hartmann, R. Traini, J. Truskina, N. Leftley, M. Hanlon, K. Swarup, A. Rashed, U. Voß, J. Alonso, A. Stepanova, J. Yun, K. Ljung, K. M. Brown, J. P. Lynch, L. Dolan, T. Vernoux, A. Bishopp, D. Wells, N. von Wirén, M. J. Bennett, R. Swarup, A mechanistic framework for auxin dependent Arabidopsis root hair elongation to low external phosphate. Nat. Commun. 9, 1409 (2018). doi:10.1038/s41467-018-03851-3 Medline

23. J. E. Salazar-Henao, I. C. Vélez-Bermúdez, W. Schmidt, The regulation and plasticity of root hair patterning and morphogenesis. Development 143, 18481858 (2016). doi:10.1242/dev.132845 Medline

24. M. Grebe, J. Friml, R. Swarup, K. Ljung, G. Sandberg, M. Terlou, K. Palme, M. J. Bennett, B. Scheres, Cell polarity signaling in Arabidopsis involves a BFA-sensitive auxin influx pathway. Curr. Biol. 12, 329-334 (2002). doi:10.1016/S09609822(02)00654-1 Medline

25. H. Rouached, A. B. Arpat, Y. Poirier, Regulation of phosphate starvation responses in plants: Signaling players and cross-talks. Mol. Plant 3, 288-299 (2010). doi:10.1093/mp/ssp120 Medline

26. Z. H. Chen, G. A. Nimmo, G. I. Jenkins, H. G. Nimmo, BHLH32 modulates several biochemical and morphological processes that respond to $\mathrm{P}_{\mathrm{i}}$ starvation in Arabidopsis. Biochem. J. 405, 191-198 (2007). doi:10.1042/BJ20070102 Medline

27. Z. Ma, D. G. Bielenberg, K. M. Brown, J. P. Lynch, Regulation of root hair density by phosphorus availability in Arabidopsis thaliana. Plant Cell Environ. 24, 459-467 (2001). doi:10.1046/j.1365-3040.2001.00695.x

28. A. Schlereth, B. Möller, W. Liu, M. Kientz, J. Flipse, E. H. Rademacher, M. Schmid, G. Jürgens, D. Weijers, MONOPTEROS controls embryonic root initiation by regulating a mobile transcription factor. Nature 464, 913-916 (2010). doi:10.1038/nature08836 Medline

29. P. Wu, L. Ma, X. Hou, M. Wang, Y. Wu, F. Liu, X. W. Deng, Phosphate starvation triggers distinct alterations of genome expression in Arabidopsis roots and leaves. Plant Physiol. 132, 1260-1271 (2003). doi:10.1104/pp.103.021022 Medline

30. E. Zürcher, D. Tavor-Deslex, D. Lituiev, K. Enkerli, P. T. Tarr, B. Müller, A robust and sensitive synthetic sensor to monitor the transcriptional output of the cytokinin signaling network in planta. Plant Physiol. 161, 1066-1075 (2013). doi:10.1104/pp.112.211763 Medline

31. K. C. Potter, J. Wang, G. E. Schaller, J. J. Kieber, Cytokinin modulates contextdependent chromatin accessibility through the type-B response regulators. Nat. Plants 4, 1102-1111 (2018). doi:10.1038/s41477-018-0290-y Medline

32. I. H. Street, D. E. Mathews, M. V. Yamburkenko, A. Sorooshzadeh, R. T. John, R. Swarup, M. J. Bennett, J. J. Kieber, G. E. Schaller, Cytokinin acts through the auxin influx carrier AUX1 to regulate cell elongation in the root. Development 143, 39823993 (2016). doi:10.1242/dev.132035 Medline

33. L. Song, H. Yu, J. Dong, X. Che, Y. Jiao, D. Liu, The molecular mechanism of ethylene-mediated root hair development induced by phosphate starvation. PLOS Genet. 12, e1006194 (2016). doi:10.1371/journal.pgen.1006194 Medline

34. S. Zhang, L. Huang, A. Yan, Y. Liu, B. Liu, C. Yu, A. Zhang, J. Schiefelbein, Y. Gan, Multiple phytohormones promote root hair elongation by regulating a similar set of genes in the root epidermis in Arabidopsis. J. Exp. Bot. 67, 6363-6372 (2016). doi:10.1093/jxb/erw400 Medline

35. T. Schmülling, T. Werner, M. Riefler, E. Krupková, I. Bartrina y Manns, Structure and function of cytokinin oxidase/dehydrogenase genes of maize, rice, Arabidopsis and other species. J. Plant Res. 116, 241-252 (2003). doi:10.1007/s10265-003-0096-4 Medline

36. G. Janes, D. von Wangenheim, S. Cowling, I. Kerr, L. Band, A. P. French, A. Bishopp,
Cellular patterning of Arabidopsis roots under low phosphate conditions. Front Plant Sci 9, 735 (2018). doi:10.3389/fpls.2018.00735 Medline

37. S. M. Brady, S. Song, K. S. Dhugga, J. A. Rafalski, P. N. Benfey, Combining expression and comparative evolutionary analysis. The COBRA gene family. Plant Physiol. 143, 172-187 (2007). doi:10.1104/pp.106.087262 Medline

38. Y. Lin, J. Schiefelbein, Embryonic control of epidermal cell patterning in the root and hypocotyl of Arabidopsis. Development 128, 3697-3705 (2001). Medline

39. M. Simon, M. M. Lee, Y. Lin, L. Gish, J. Schiefelbein, Distinct and overlapping roles of single-repeat MYB genes in root epidermal patterning. Dev. Biol. 311, 566-578 (2007). doi:10.1016/i.ydbio.2007.09.001 Medline

40. M. Bonke, S. Thitamadee, A. P. Mähönen, M. T. Hauser, Y. Helariutta, APL regulates vascular tissue identity in Arabidopsis. Nature 426, 181-186 (2003). doi:10.1038/nature02100 Medline

41. J. M. Alonso, T. Hirayama, G. Roman, S. Nourizadeh, J. R. Ecker, EIN2, a bifunctional transducer of ethylene and stress responses in Arabidopsis. Science 284, 2148-2152 (1999). doi:10.1126/science.284.5423.2148 Medline

42. T. Potuschak, E. Lechner, Y. Parmentier, S. Yanagisawa, S. Grava, C. Koncz, P. Genschik, EIN3-dependent regulation of plant ethylene hormone signaling by two Arabidopsis F box proteins: EBF1 and EBF2. Cell 115, 679-689 (2003). doi:10.1016/S0092-8674(03)00968-1 Medline

43. M. K. Zhiponova, K. Morohashi, I. Vanhoutte, K. Machemer-Noonan, M. Revalska, M. Van Montagu, E. Grotewold, E. Russinova, Helix-loop-helix/basic helix-loophelix transcription factor network represses cell elongation in Arabidopsis through an apparent incoherent feed-forward loop. Proc. Natl. Acad. Sci. U.S.A. 111, 28242829 (2014). doi:10.1073/pnas.1400203111 Medline

44. J. Goossens, G. Swinnen, R. Vanden Bossche, L. Pauwels, A. Goossens, Change of a conserved amino acid in the MYC2 and MYC3 transcription factors leads to release of JAZ repression and increased activity. New Phytol. 206, 1229-1237 (2015). doi:10.1111/nph.13398 Medline

45. A. Coego, E. Brizuela, P. Castillejo, S. Ruíz, C. Koncz, J. C. del Pozo, M. Piñeiro, J. A. Jarillo, J. Paz-Ares, J. León; TRANSPLANTA Consortium, The TRANSPLANTA collection of Arabidopsis lines: A resource for functional analysis of transcription factors based on their conditional overexpression. Plant J. 77, 944-953 (2014). doi:10.1111/tpj.12443 Medline

46. A. S. Iyer-Pascuzzi, P. N. Benfey, Fluorescence-activated cell sorting in plant developmental biology. Methods Mol. Biol. 655, 313-319 (2010). doi:10.1007/978-1-60761-765-5 21 Medline

47. A. T. Lun, K. Bach, J. C. Marioni, Pooling across cells to normalize single-cell RNA sequencing data with many zero counts. Genome Biol. 17, 75 (2016). doi:10.1186/s13059-016-0947-7 Medline

48. A. T. Lun, D. J. McCarthy, J. C. Marioni, A step-by-step workflow for low-level analysis of single-cell RNA-seq data with Bioconductor. F1000Res. 5, 2122 (2016). doi:10.12688/f1000research.9501.2 Medline

49. C. S. McGinnis, L. M. Murrow, Z. J. Gartner, DoubletFinder: Doublet detection in single-cell RNA sequencing data using artificial nearest neighbors. Cell Syst. 8 , 329-337.e4 (2019). doi:10.1016/i.cels.2019.03.003 Medline

50. K. Birnbaum, D. E. Shasha, J. Y. Wang, J. W. Jung, G. M. Lambert, D. W. Galbraith P. N. Benfey, A gene expression map of the Arabidopsis root. Science 302, 19561960 (2003). doi:10.1126/science.1090022 Medline

51. W. Saelens, R. Cannoodt, H. Todorov, Y. Saeys, A comparison of single-cell trajectory inference methods. Nat. Biotechnol. 37, 547-554 (2019). doi:10.1038/s41587-019-0071-9 Medline

52. K. Street, D. Risso, R. B. Fletcher, D. Das, J. Ngai, N. Yosef, E. Purdom, S. Dudoit, Slingshot: Cell lineage and pseudotime inference for single-cell transcriptomics. BMC Genomics 19, 477 (2018). doi:10.1186/s12864-018-4772-0 Medline

53. L. Muñiz, E. G. Minguet, S. K. Singh, E. Pesquet, F. Vera-Sirera, C. L. MoreauCourtois, J. Carbonell, M. A. Blázquez, H. Tuominen, ACAULIS5 controls Arabidopsis xylem specification through the prevention of premature cell death. Development 135, 2573-2582 (2008). doi:10.1242/dev.019349 Medline

54. A. Carlsbecker, J.-Y. Lee, C. J. Roberts, J. Dettmer, S. Lehesranta, J. Zhou, 0. Lindgren, M. A. Moreno-Risueno, A. Vatén, S. Thitamadee, A. Campilho, J. Sebastian, J. L. Bowman, Y. Helariutta, P. N. Benfey, Cell signalling by microRNA165/6 directs gene dose-dependent root cell fate. Nature 465, 316-321 (2010). doi:10.1038/nature08977 Medline

55. M. Kubo, M. Udagawa, N. Nishikubo, G. Horiguchi, M. Yamaguchi, J. Ito, T. Mimura, 
H. Fukuda, T. Demura, Transcription switches for protoxylem and metaxylem vessel formation. Genes Dev. 19, 1855-1860 (2005). doi:10.1101/gad.1331305 Medline

56. M. Taylor-Teeples, L. Lin, M. de Lucas, G. Turco, T. W. Toal, A. Gaudinier, N. F. Young, G. M. Trabucco, M. T. Veling, R. Lamothe, P. P. Handakumbura, G. Xiong, C. Wang, J. Corwin, A. Tsoukalas, L. Zhang, D. Ware, M. Pauly, D. J. Kliebenstein, K. Dehesh, I. Tagkopoulos, G. Breton, J. L. Pruneda-Paz, S. E. Ahnert, S. A. Kay, S. P. Hazen, S. M. Brady, An Arabidopsis gene regulatory network for secondary cell wall synthesis. Nature 517, 571-575 (2015). doi:10.1038/nature14099 Medline

57. S. Otero, Y. Helariutta, Companion cells: A diamond in the rough. J. Exp. Bot. 68 , 71-78 (2017). doi:10.1093/jxb/erw392 Medline

58. V. López-Salmerón, H. Cho, N. Tonn, T. Greb, The phloem as a mediator of plant growth plasticity. Curr. Biol. 29, R173-R181 (2019). doi:10.1016/i.cub.2019.01.015 Medline

59. J. R. Wendrich, C. Y. Liao, W. A. van den Berg, B. De Rybel, D. Weijers, Ligationindependent cloning for plant research. Methods Mol. Biol. 1284, 421-431 (2015). doi:10.1007/978-1-4939-2444-8 21 Medline

60. R. Siligato, X. Wang, S. R. Yadav, S. Lehesranta, G. Ma, R. Ursache, I. Sevilem, J. Zhang, M. Gorte, K. Prasad, M. Wrzaczek, R. Heidstra, A. Murphy, B. Scheres, A. P. Mähönen, MultiSite gateway-compatible cell type-specific gene-inducible system for plants. Plant Physiol. 170, 627-641 (2016). doi:10.1104/pp.15.01246 Medline

61. S. J. Clough, A. F. Bent, Floral dip: A simplified method for Agrobacteriummediated transformation of Arabidopsis thaliana. Plant J. 16, 735-743 (1998). doi:10.1046/j.1365-313x.1998.00343.x Medline

62. R. Ursache, T. G. Andersen, P. Marhavý, N. Geldner, A protocol for combining fluorescent proteins with histological stains for diverse cell wall components. Plant J. 93, 399-412 (2018). doi:10.1111/tpj.13784 Medline

63. E. Truernit, H. Bauby, B. Dubreucq, O. Grandjean, J. Runions, J. Barthélémy, J.-C. Palauqui, High-resolution whole-mount imaging of three-dimensional tissue organization and gene expression enables the study of phloem development and structure in Arabidopsis. Plant Cell 20, 1494-1503 (2008). doi:10.1105/tpc.107.056069 Medline

64. P. Barbier de Reuille, A.-L. Routier-Kierzkowska, D. Kierzkowski, G. W. Bassel, T. Schüpbach, G. Tauriello, N. Bajpai, S. Strauss, A. Weber, A. Kiss, A. Burian, H. Hofhuis, A. Sapala, M. Lipowczan, M. B. Heimlicher, S. Robinson, E. M. Bayer, K. Basler, P. Koumoutsakos, A. H. K. Roeder, T. Aegerter-Wilmsen, N. Nakayama, M. Tsiantis, A. Hay, D. Kwiatkowska, I. Xenarios, C. Kuhlemeier, R. S. Smith MorphoGraphX: A platform for quantifying morphogenesis in 4D. eLife 4, e05864 (2015). doi:10.7554/eLife.05864 Medline

65. B. De Rybel, V. Vassileva, B. Parizot, M. Demeulenaere, W. Grunewald, D. Audenaert, J. Van Campenhout, P. Overvoorde, L. Jansen, S. Vanneste, B. Möller, M. Wilson, T. Holman, G. Van Isterdael, G. Brunoud, M. Vuylsteke, T. Vernoux, L. De Veylder, D. Inzé, D. Weijers, M. J. Bennett, T. Beeckman, A novel aux/IAA28 signaling cascade activates GATA23-dependent specification of lateral root founder cell identity. Curr. Biol. 20, 1697-1706 (2010). doi:10.1016/i.cub.2010.09.007 Medline

66. H. Wickham, ggplot2, Elegant Graphics for Data Analysis (Use R!) (Springer, 2009), vol. 1, pp. VIII, 213.

\section{ACKNOWLEDGMENTS}

The authors would like to thank Veronique Storme for help with statistical analyses and Dolf Weijers for the use of unpublished materials. Funding: This work was supported by funding from the European Research Council (ERC Starting Grant TORPEDO; 714055), the Research Foundation - Flanders (FWO; Odysseus II G0D0515N); Ghent University (BOF20/GOA/012 and BOF18/PD0/151) and a Marie Curie Fellowship (IEF-2009-252503). Author contributions: B.D.R., Y.S. and G.V.I. conceived the project; B.D.R., J.R.W. and B.Y. designed experiments; J.R.W., J.V.D., B.D.R. and G.V.I. generated samples for scRNA-seq; N.V.D. performed single cell RNA sequencing; N.V.D., K.V. and Y.S. analyzed scRNA-seq data and trajectory analysis; K.V. generated the on-line browser tool; W.S., B.W., E.M., H.E.A., J.N., B.Y. and J.R.W. generated reporter lines to validate the dataset; S.M. performed ploidy analysis; B.Y., C.V.d.V, M.M. and J.R.W. analyzed effects on root hair growth; B.D.R. and Y.S. supervised the project; B.D.R. wrote the paper with input from all authors. Competing interests: None declared. Data and materials availability: The single cell data can be accessed via a freely accessible on-line browser tool (https://bioit3.irc.ugent.be/plant-sc-atlas/) and raw data can be accessed at NCBI with GEO number: GSE141730. All other data needed to evaluate the conclusions in the paper are present in the paper or the supplementary materials. Material requests should be directed to the corresponding authors.

\section{SUPPLEMENTARY MATERIALS}

science.sciencemag.org/cgi/content/full/science.aay4970/DC1

Materials and Methods

Figs. S1 to S23

Tables S1 to S3

References (40-66)

MDAR Reproducibility Checklist

24 June 2019; resubmitted 17 July 2020

Accepted 4 September 2020

Published online 17 September 2020

10.1126/science.aay4970 


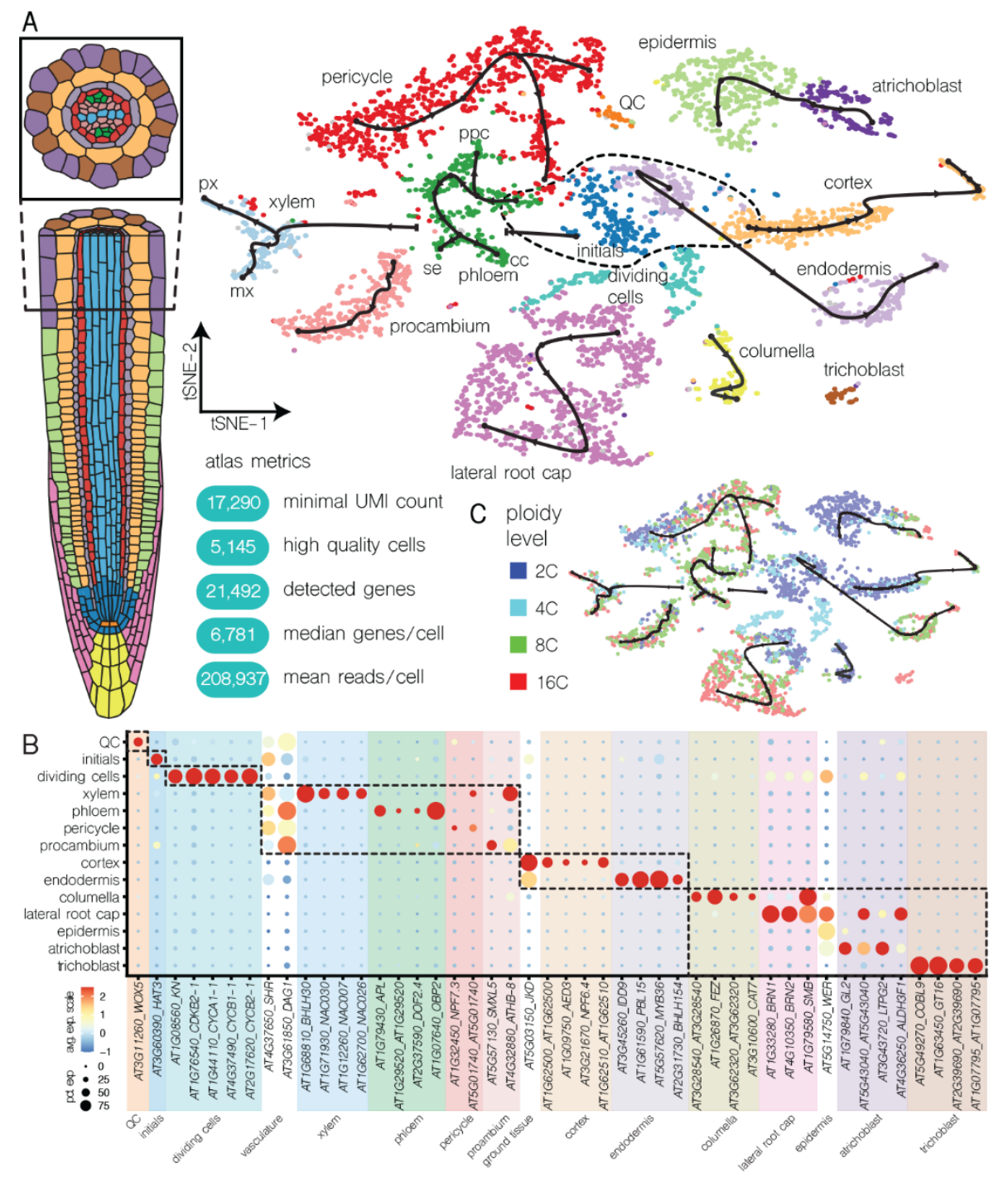

Fig. 1. Identification of Arabidopsis root meristem cell types using scRNA-seq. (A) Color-coded tSNE plot showing the classification of 5,145 high quality (UMI count $>17,290$ ) cells into distinct cell identities corresponding to the schematic representation of the root meristem on the left. Grey dots represent predicted doublet cells. All inferred and validated developmental trajectories are projected onto the tSNE plot as black lines. Cells within dotted line are initials. QC: quiescent center, ppc: phloem procambium, se: sieve element, cc: companion cell, px: protoxylem, mx: metaxylem. (B) Dot plot showing the expression of known tissue specific reporter genes in the scRNA-seq dataset, validating the annotation of tissue specific clusters. Size of the circles represents the percentage of cells with expression (pct.exp.), while the color indicates the scaled average expression (avg exp. scale). Dotted boxes represent major tissue types and cellular stages present in the root. (C) Projection of predicted ploidy levels of each cell onto the tSNE plot. 


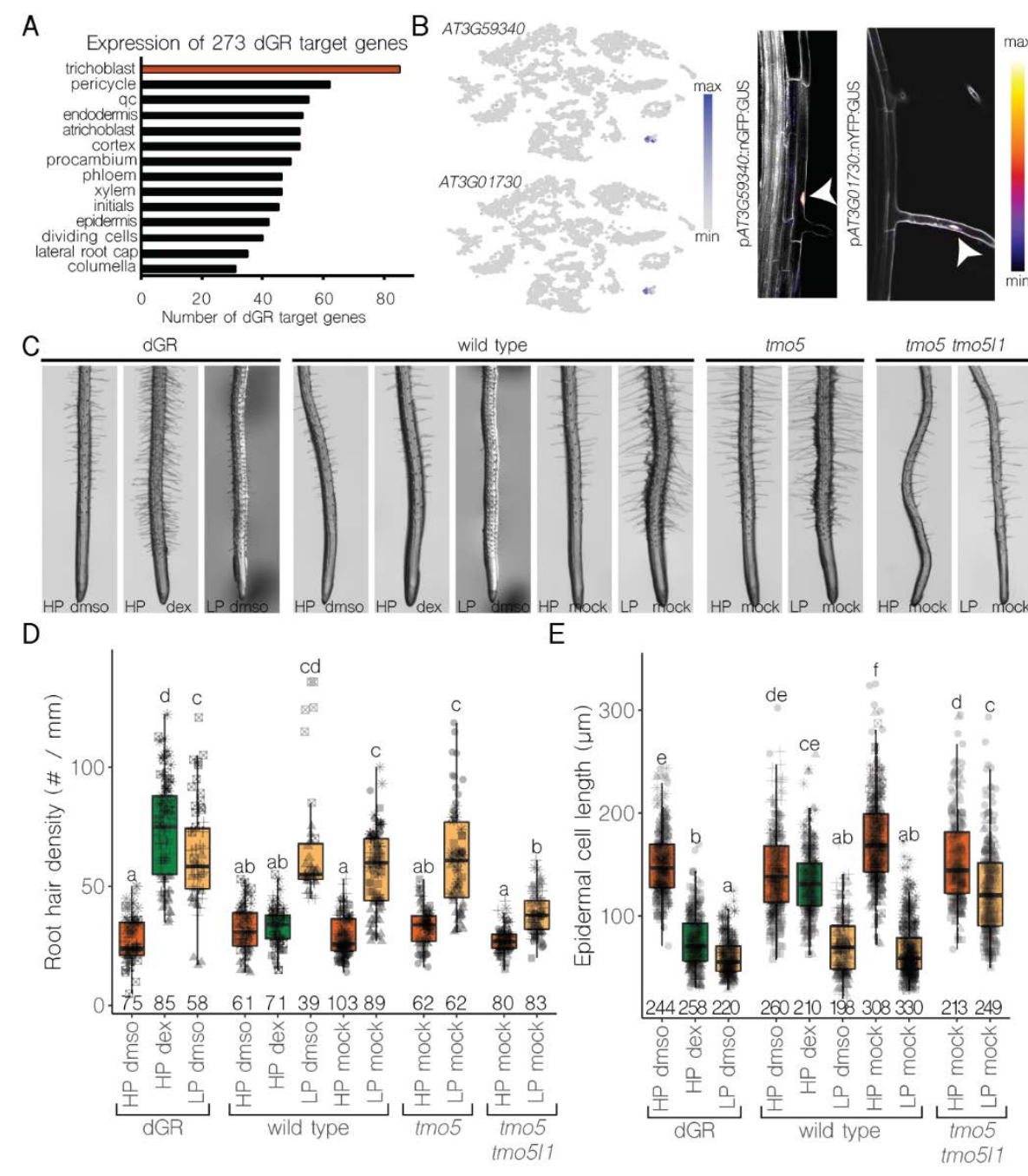

Fig. 2. TMO5 activity is required for root hair responses to low phosphate conditions. (A) Number of TMO5/LHW target genes expressed in each of the tissue types of the Arabidopsis root meristem. Note the high number of trichoblast expressed genes. (B) Predicted (left) and validated (right) expression of root hair specific target genes in the root hair. Arrowheads indicate nuclear expression. (C) Root hair phenotype of dGR (induced or non-induced with dex) and wild type, tmo5 single mutant and tmo5 tmo5likel double mutants grown on control conditions (high phosphate) or phosphate limiting conditions (low phosphate). ( $D$ and $E$ ) Quantification of the root hair density (D) and epidermal cell length (E) of the lines depicted in (C). Lower case letters on top of boxplots indicate significantly different groups as determined by one-way ANOVA with post-hoc Tukey HSD testing $(p<0.001)$; the number of individuals is shown at the bottom of the plot and biological repeats are indicated using different symbols. 
A

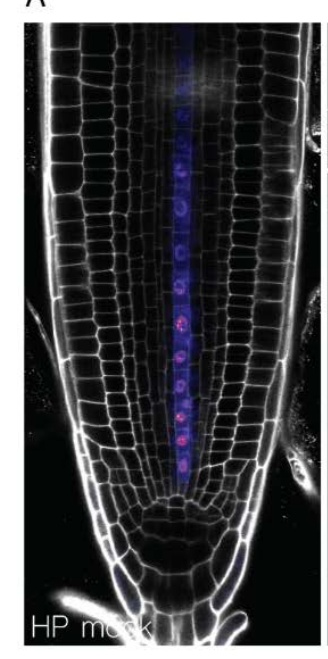

C

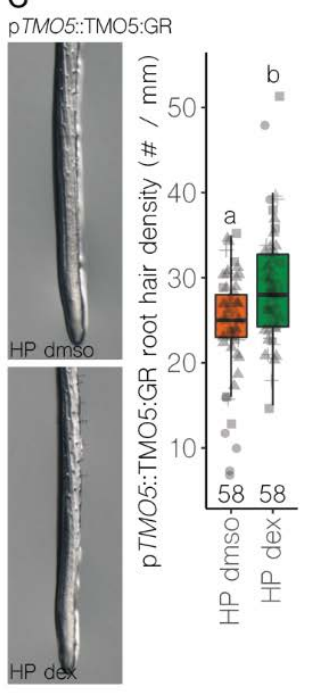

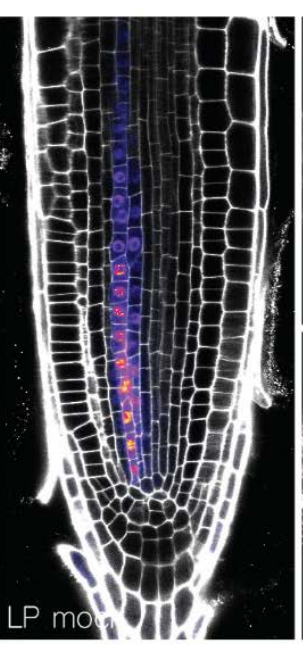

D

PSHR:TMOS:GR

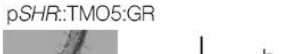

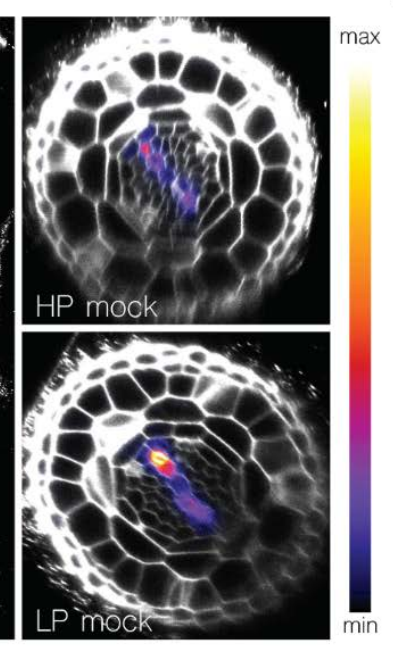

$\mathrm{E}$

wild type $\quad$ WWOL::XVE〉>TMO5:YFP
B

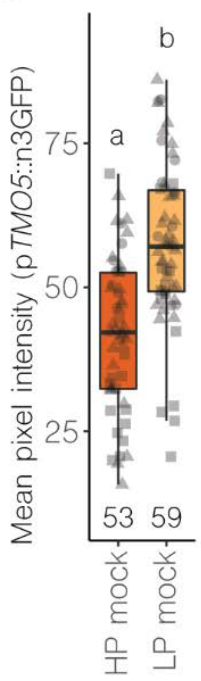

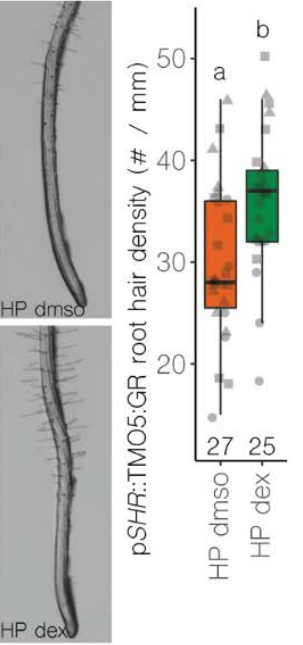
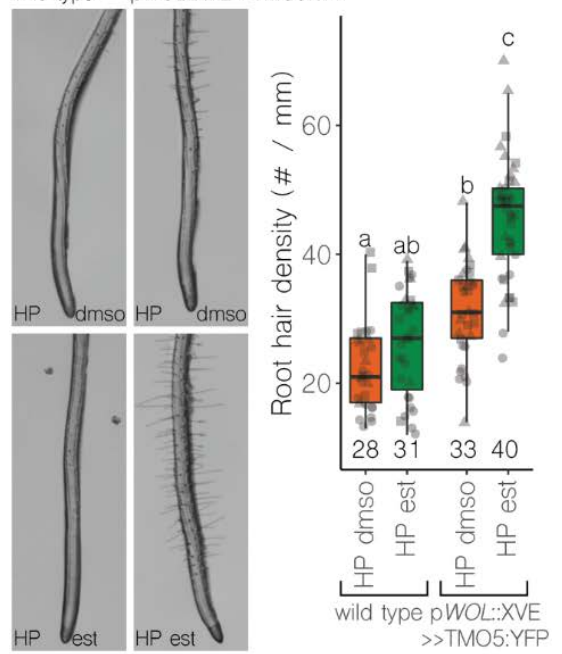

Fig. 3. Vascular TMO5/LHW expression increases root hair density. ( $A$ and B) Expression (A) and quantification (B) of the pTMO5::n3GFP reporter line in the root meristem under high (HP) and low (LP) phosphate conditions by confocal microscopy. (C to E) Root hair phenotype and quantification of wild type, pTMO5::TMO5:GR, pSHR::TMO5:GR and pWOL::XVE>>TMO5:YFP roots grown on high phosphate conditions or induced by dexamethasone or estradiol (see Fig. 2 for wild type control). Lower case letters on top of boxplots indicate significantly different groups as determined by oneway ANOVA with post-hoc Tukey HSD testing $[p<0.001$ in $(C)$ and $(E), p<0.01$ in (D)]; the number of individuals is shown at the bottom of the plot and biological repeats are indicated using different symbols. 
A

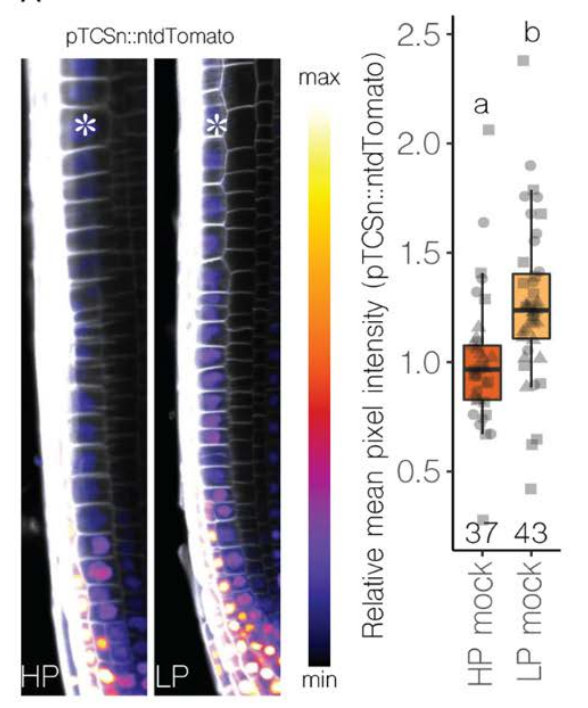

C

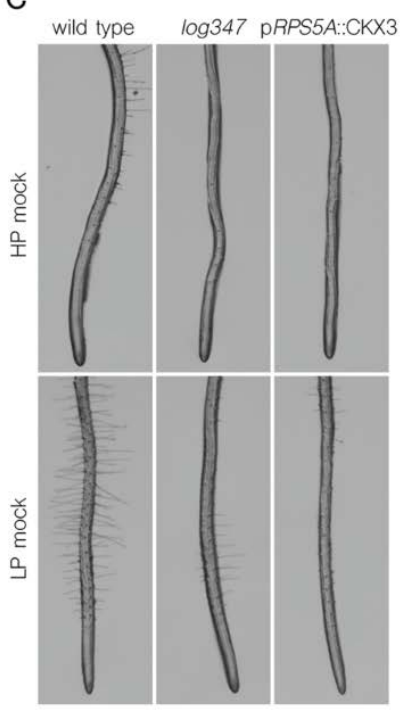

B
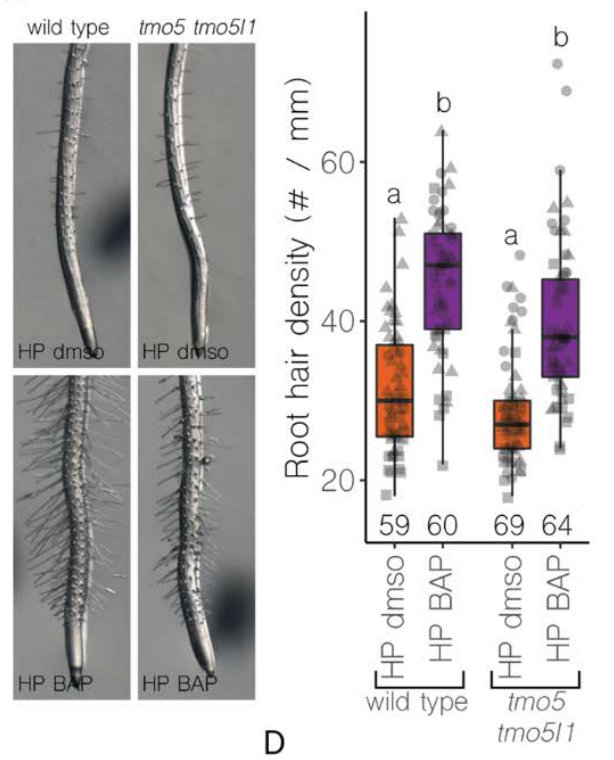

D

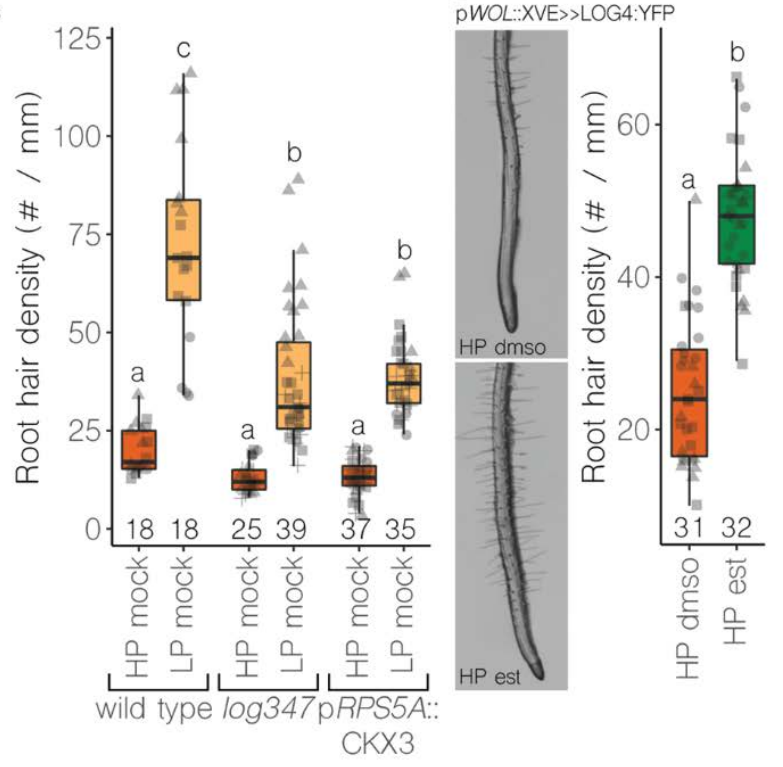

Fig. 4. TMO5/LHW dependent cytokinin triggers root hair responses. (A) Expression and quantification of pTCSn::ntdTomato in the root meristem under high (HP) and low (LP) phosphate conditions by confocal microscopy. Asterisks indicates epidermal cell layer. (B) Root hair phenotype and quantification of wild type and tmo5 tmo5like1 roots grown on high phosphate conditions or induced by cytokinin (BAP). (C) Root hair phenotype and quantification of wild type and log347 and pRPS5A::CKX3 roots grown on high or low phosphate conditions. (D) Root hair phenotype and quantification of pWOL::XVE>>LOG4:YFP roots grown high phosphate conditions or induced by estradiol (see Fig. 3 for wild type control). Lower case letters on top of boxplots indicate significantly different groups as determined by one-way ANOVA with post-hoc Tukey HSD testing $(p<0.001)$; the number of individuals is shown at the bottom of the plot and biological repeats are indicated using different symbols. 


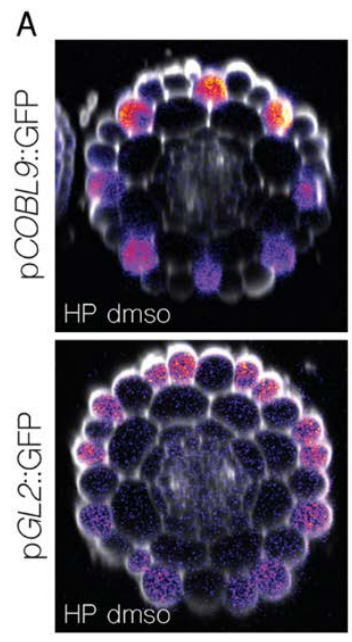

C

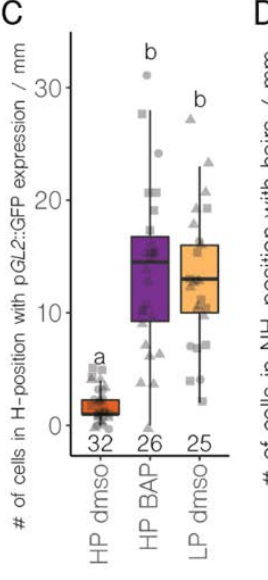

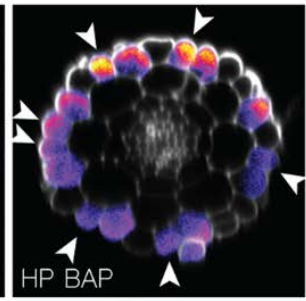

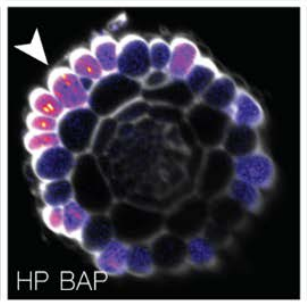

D
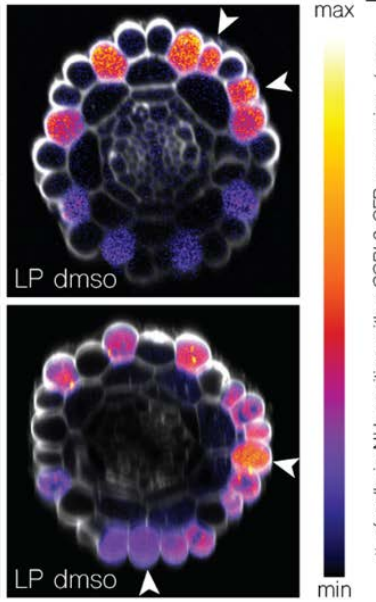

$\mathrm{E}$

max $B$
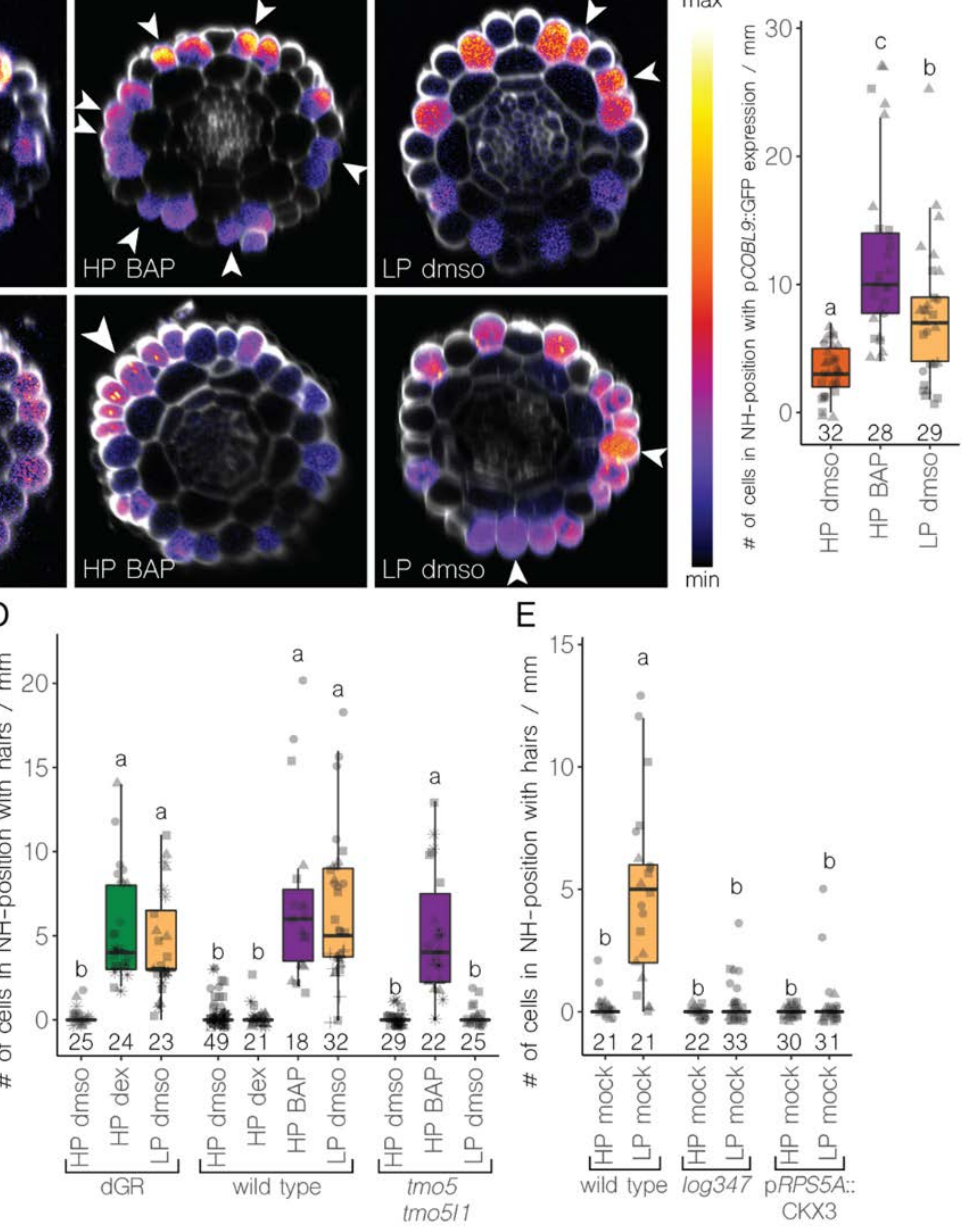

Fig. 5. Cytokinin scrambles epidermal cell identities. (A) Expression of pCOBL9::GFP and pGL2::GFP in roots grown in high phosphate (HP), cytokinin (BAP), or low phosphate (LP). (B and C) Quantification of number of cells per mm of root in non-hair $(\mathrm{NH})$ or hair $(\mathrm{H})$ positions with GFP expression. ( $D$ and $E$ ) Quantification of the number of cells in non-hair position that form root hairs, along one mm of root from dGR, wild type, tmo5, tmo5 tmo5/1, log347 or pRPS5A::CKX3 grown under indicated conditions. Lower case letters on top of the boxplots indicate significantly different groups as determined by one-way ANOVA with post-hoc Tukey HSD testing $(p<0.001)$; the number of individuals is shown at the bottom of the plot and biological repeats are indicated using different symbols. 
